\title{
SITUAÇÃO, SUBJETIVIDADE E APELO EM PYRRHUS ET CINÉAS DE SIMONE DE BEAUVOIR
}

\author{
SITUATION, SUBJECTIVITY AND APPEAL IN SIMONE DE BEAUVOIR'S PYRRHUS ET CINÉAS
}

Nathan Menezes Amarante Teixeira*

\section{RESUMO}

Em seu primeiro ensaio filosófico, Pyrrhus et Cinéas, Simone de Beauvoir busca fundamentalmente marcar a indissolúvel interdependência da liberdade humana a partir do entrelaçamento das situações. Temos ainda a colocação de que é a partir de sua noção de situação que se abre um lugar privilegiado para compreensão da ambiguidade de nosso existir no mundo e ainda para a contestação da aparente indiferença das ações frente à reflexão. Nesse contexto emerge a compreensão de Beauvoir acerca das noções de situação, subjetividade e apelo, mostrando-se como centrais para a estrutura argumentativa de seu texto. Portanto, tal texto é de suma importância para a compreensão do desenvolvimento de seu pensamento, e é nesse viés que buscaremos oferecer uma leitura de Pyrrhus et Cinéas que permita a apresentação concisa da significação desses termos, destacando-se sua importância para a caracterização do pensamento ético-existencial de Simone de Beauvoir.

PALAVRAS-CHAVE: Simone de Beauvoir. Situação. Subjetividade. Apelo. Ética.

\begin{abstract}
In her first philosophical essay Pyrrhus et Cinéas, Simone de Beauvoir fundamentally seeks to mark the indissoluble interdependency of human liberty from the interweaving of situations. We still have the postulation that it is from her notion of situation that opens up a privileged place to understand the ambiguity of our existence in the world and also to challenge the apparent indifference of our actions to reflection. In this context emerges Simone de Beauvoir's understanding about the notions of situation, subjectivity and appeal, which are central to the argumentative structure of her text. Therefore, the text is fundamentally important for understanding the development of his thought, and it is in this perspective that will be offered a reading of Pyrrhus et Cinéas that allows the concise presentation of the meaning of these terms, highlighting its importance for characterization of Simone de Beauvoir's ethical - existential thought.
\end{abstract}

KEY-WORDS: Simone de Beauvoir. Situation. Subjectivity. Appeal. Ethics.

Pyrrhus et Cinéas é o primeiro ensaio filosófico de Simone de Beauvoir, escrito durante a ocupação nazista na França e publicado em 1944 após o fim desta e, como colocado pela própria autora no segundo volume de sua autobiografia, La force de l'age, tratava-se de "fornecer um conteúdo material à moral existencialista" (BEAUVOIR, 2015, p. 711). O contexto da escrita de tal texto é dado quando, no início de 1943, Sartre apresenta Simone de

\footnotetext{
* Doutorando em Filosofia pela UFRJ, com pesquisa na linha de Ética, e pesquisador estudante do laboratório Escritas - filosofia, gênero e psicanálise (CNPq); e-mail: nathanmateixeira @ gmail.com.
} 
Beauvoir a Jean Grenier ${ }^{1}$, que na época "projetava reunir em volumes ensaios manifestando as tendências ideológicas da época" (BEAUVOIR, 2015, p. 708). Assim, Grenier propõe que Beauvoir contribua com sua coletânea, escrevendo um texto sobre o existencialismo, algo que ela recusa de início, mas acaba por aceitar uma vez que, "acerca de certas questões que eu pusera em $O$ sangue dos outros, restavam-me algumas coisas a dizer, em particular sobre a relação entre a experiência individual e a realidade universal” (p. 709).

É preciso desde já deixar marcado a importância fundamental desse texto para o desenvolvimento do pensamento de Simone de Beauvoir, uma vez que é onde a autora estrutura diretamente pela primeira vez suas considerações próprias, até então existentes como indicações presentes apenas em seus Cahiers du jeunesse. Não trabalharemos aqui tais textos de juventude, no entanto cumpre apontar que desde as anotações de 1926-27, por exemplo, observa-se a discussão contínua de temáticas existenciais, desdobradas posteriormente ${ }^{2}$. Tal estruturação nos apresenta ainda a influência em seu pensamento de certos pressupostos de Sartre presentes em L'être et le néant, em que se mostram modificadas certas noções bases dessa obra. Assim, é esse esquema inicial construído em 44 com preocupações fundamentalmente éticas que forma a base de seu pensamento ético-existencial e desdobrarse-ão de forma mais trabalhada no seu texto de 1947 Pour une morale de l'ambiguité ${ }^{3}$. Por sua vez, quando na introdução do Vol. I de Le deuxième sexe publicado em 1949, Beauvoir diz que "a perspectiva que adotamos é aquela da moral existencialista" (BEAUVOIR, 2016, p. 33), é preciso compreender que é em relação a esses dois textos iniciais que a autora faz referência; em suma, toda a estrutura de argumentação do texto de 49 está dada a partir de seu pensamento ético tal como formulado nos textos anteriores, ainda que haja acréscimos significativos que são devidamente compreendidos se nos atentarmos a essas formulações éticas iniciais.

Anteriormente já foi exposta uma consideração significativa sobre as intenções textuais da autora, qual seja, de trabalhar melhor a questão da relação entre experiência

\footnotetext{
${ }^{1}$ Jean Grenier foi filósofo e escritor francês, que lecionou na Argélia onde teve Albert Camus como aluno no início de 1930.

${ }^{2}$ Margareth Simmons, no último capítulo de seu texto Simone de Beauvoir and The second sex: feminism, race and the origins of existentialism, busca mostrar precisamente o modo em que questões como a busca do ser, o nada como constitutivo dessa busca e que a faz ser contínua, e a má-fé, por exemplo, já aparecem nos Cahiers de Beauvoir. Sobre isso ver: Simmons (1999, p. 206-233).

${ }^{3}$ Destacamos a colocação de Kristen Oganowski de que "antecipando seus argumentos de Pour une morale de l'ambiguité, Beauvoir argumenta em Pyrrhus et Cinéas que o estado relacional [relationality] dos seres humanos ajuda a estabelecer a liberdade de cada indivíduo" (OGANOWSKI, 2013, p. 74).
} 
individual e realidade universal ${ }^{4}$. Porém outro apontamento presente no volume de sua autobiografia anteriormente citada mostra-se igualmente fundamental:

Tentei, assim, conciliar [concilier] com as ideias de Sartre a tendência que, em longas discussões, eu sustentara contra ele [j'avais soutenue contre lui]: restabelecia uma hierarquia entre as situações [je rétablissais une hiérarchie entre les situations]; subjetivamente a salvação era em todo caso possível; não se devia, contudo, deixar de preferir o saber à ignorância, a saúde à doença, a prosperidade à penúria. (BEAUVOIR, 2015, p. 710, grifos nossos).

Observamos a partir da citação que Beauvoir compreende a noção de situação de modo diferente de Sartre, fundamentalmente na perspectiva de que para ela as situações não são todas equivalentes, de modo a ser possível hierarquizá-las. Trata-se aqui de referência direta ao modo como esse termo é exposto em L'être et le néant, em que Sartre considera que não haveria situações melhores ou piores do ponto de vista da realização existencial da liberdade, uma vez que a estrutura da consciência do para-si (modo de ser fundamental dos seres humanos que existe a partir da característica principal da consciência, que é negar o dado à luz do seu projeto) é tal que toda a espessura de ser da situação é projetada pela consciência a partir da distância negadora que ela mesma é ${ }^{5}$. Ou seja, o estar situado no mundo da liberdade humana seria mero meio passivo e negativo, no sentido de que este não conta nem contribui para seu existir, este é vivido na síntese negativa da consciência já como em-si negado. .

Desde já importa frisar, portanto, que Simone de Beauvoir pensa que há sim como estabelecer uma diferenciação entre as situações posto que estas atuam ativamente sobre a liberdade, apesar de essa atuação não ser ao modo de uma determinação causal. Trata-se então do apontamento da autora de que em Pyrrhus et Cinéas estaria em jogo o mostrar "a verdade e importância da ideia de situação introduzida por Sartre [...]" (BEAUVOIR, 2013, p. 540, grifos nossos); em outros termos, Beauvoir aceita de Sartre a introdução na discussão existencial sobre a liberdade da noção de situação, o que é de suma importância tendo em

\footnotetext{
${ }^{4}$ Este "trabalhar melhor" diz respeito, como visto na passagem citada no primeiro parágrafo, ao que já havia sido exposto em seu romance de 1943, Les sang des autres, sobre esse mesmo tema da relação ambígua entre o indivíduo situado singularmente no mundo e a realidade social enquanto solo comum no qual existe "enredado"com os outros. Não trabalharemos aqui essa diferença entre obras, apenas marcamos que Beauvoir entende que sua colocação desse problema em 1943 ainda precisava de algo mais, e isto é importante de ser ter em consideração enquanto motivação significativa da escrita do ensaio em questão, uma vez que é precisamente essa ambiguidade existencial que se constituirá como exposição fundamental do texto.

${ }^{5}$ Sartre diz: "Nós denominaremos situação a contingência da liberdade no plenum de ser no mundo na medida em que este datum, que está lá apenas para não constranger a liberdade, não se revela a esta liberdade se não como já iluminado pelo fim que ela escolheu." (SARTRE, 2016, p. 646, grifos do autor).
} 
vista que uma está sempre relacionada a outra, entretanto, faltaria ainda mostrar sua verdade, o significado que para Beauvoir seria mais apropriado e que diz respeito ao modo como se dá a relação entre ambas, e só então poder-se-á mostrar sua importância. Isso implicando também, como veremos, a colocação de sua própria compreensão de outros termos envolvidos.

A partir dessas considerações dadas pela própria Simone de Beauvoir, temos que seu texto de 1944 visava articular objetivamente sua compreensão própria da noção de situação e a relação entre o indivíduo situado e a "realidade universal" como conjunto das situações, de tal modo que ganhe corpo uma necessidade ética que estaria vinculada desde o princípio e de modo indissolúvel às análises existenciais acerca de nossa condição no mundo. Nesse âmbito, como aponta Debra Bergoffen, é central ao texto em foco responder à "questão existencial, Porque (sic) agir?" (BERGOFFEN, 2004, p. 82), em que ficará marcada a consideração de Beauvoir de que dar conta adequadamente dessa questão envolve inevitavelmente dar conta também da pergunta sobre nossa situação enquanto lugar a partir do qual nossos projetos tornam-se possíveis.

Assim, nos voltando propriamente para o texto, temos que ele é iniciado com um diálogo fictício entre os personagens históricos Pirro, rei da Macedônia, e Cíneas seu conselheiro, acerca dos planos de Pirro para conquistar o mundo. A problemática inicia-se quando Pirro afirma a Cíneas que, após o término da conquista, ele apenas retornará a casa para descansar, o que parece ser aos olhos do último algo sem sentido; para Cíneas, se ao fim tratar-se-á de retornar ao ponto de partida, agir torna-se algo fútil, e manter-se em repouso no presente seria melhor do que iniciar projetos que terão fim e conduzirão sempre novamente ao repouso ${ }^{6}$.

\footnotetext{
${ }^{6}$ Importante marcar aqui que se trata do desdobramento de uma temática presente já na formulação inicial de seu pensamento nos Cahiers de jeunesse. Em La force de l'âge, na mesma sequência de explicitação do contexto de escrita de Pyrrhus et Cinéas que citamos no início deste trabalho, Simone de Beauvoir afirma que "este diálogo entre Pirro e Cinéias lembra aquele que se desenvolveu de mim mesma a mim mesma e que anotei em meu diário íntimo [...]; nos dois casos, uma voz demandava: Para quê? [À quoi bon?]" (BEAUVOIR, 2015, p. 711). Trata-se da referência da autora à problemática central a ser desenvolvida no texto de 44 - a possibilidade de constatação da inutilidade do fazer/agir por conta do vazio como elemento constitutivo do movimento contínuo do existir humano - que já era assim trabalhado desde esses textos de juventude, como vemos em: "Eu me disse 'é preciso buscar, caminhar [marcher]; eu não tenho o direito de permanecer assim', e logo em seguida 'para quê [à quoi bon], em relação a quê, em relação a quem', e de fato, a este 'para quế' eu não posso nada responder [...]; mas eu não tenho o direito de lhe dizer que, uma vez ido além, eu irei encontrar verdadeiramente que não há nada" (BEAVOIR, 2008, p. 375). Como se vê, trata-se aqui da ambiguidade existencial presente no fato de que se é sempre como projeto de si constante, fazer ser como movimento que, marcado pelo vazio ambíguo que lhe constitui, sempre tem aberta a possibilidade de afastar-se do vivido e olhar reflexivamente com indiferença ao próprio existir que se é como "caminhada [marche]" constante. Por fim, como nos diz Beauvoir vinculando o texto da juventude com Pyrrhus et Cinéas, "hoje como ontem a resposta era a mesma: opunha à razão inerte, ao
} 
Trata-se, fundamentalmente, de uma discussão acerca dos limites que continuamente cercam nossos projetos e do modo como essa limitação é encarada pela reflexão. Simone de Beauvoir aponta então que "Cíneas parece sensato" (BEAUVOIR, 2013, p. 201), na medida em que "[...] aos olhos da reflexão, todo projeto humano parece absurdo, pois este existe apenas ao se atribuir limites, os quais podem ser sempre transpostos, perguntando-se com desdém: 'por que até lá? Por que não mais além? [...]”' (p. 202). Porém, como fica desde já marcado, a sensatez de Cíneas é meramente aparente, é uma conclusão apressada apoiada na perspectiva equivocada de que caberia exclusivamente ao ponto de vista da reflexão estabelecer uma análise sobre os fins e limites dos projetos humanos, ou seja, que seria a partir de uma consideração meramente abstrata sobre a finalidade do agir que poderíamos caracterizar e justificar nossas ações. Desse modo, é ao constatar que reflexivamente os limites dos projetos humanos podem sempre ser negados em nome de outros limites mais longínquos, que Cinéas conclui que não há fins aceitáveis e que "já não existe para ele senão ocupações vãs" (p. 202) ${ }^{7}$.

É preciso ter em mente que Simone de Beauvoir utiliza o termo reflexão [réflexion] como sinônimo da atividade da consciência em geral, cuja característica principal é ser a nadificação distanciadora do dado, e de si mesmo. Tal definição mantém como base a ideia geral dada por Sartre, quando afirma que "o ser da consciência, enquanto consciência, consiste em existir à distância de si como presença a si, e essa distância nula que o ser traz em seu ser é o Nada" (SARTE, 2016, p. 135, grifo do autor). Porém, Sartre diferencia dois modos de consciência, o cógito pré-reflexivo que é o modo primário pelo qual experenciamos o mundo e realiza a negação primeira do em-si (dado bruto iluminado a partir da negatividade trazida ao mundo pelo para-si) no qual não há um eu atrelado a ele, e a atividade reflexiva que realizaria uma outra negação postulando um eu para refletir sobre experiências passadas. Assim, Beauvoir admite, como nos diz diretamente na conclusão de seu texto, que a dimensão consciente do sujeito mostra-se como atividade reflexiva que "faz surgir em torno de mim o nada" (BEAUVOIR, 2013, p. 313), mas sem estabelecer a diferenciação entre dois modos da consciência no seu atuar, justamente porque para ela o modo primário de experenciarmos o

nada [j'opposai à la raison inerte, au néant], a inelutável evidência de uma afirmação viva [l'inéluctable évidence d'une affirmation vivante]" (BEAUVOIR, 2015, p. 711).

7 Importante destacar a colocação de Debra Bergoffen que melhor especifica esse modo de consideração manifesto a partir de Cinéas, de que "seu argumento não é o de que sempre falho ao tentar concluir um projeto com sucesso, mas sim que todos os projetos são por definição sem sucesso. O problema não é que eu falhe no exame que tento passar, mas sim que passando no exame meu projeto permanece inconcluso" (BERGOFFEN, 1997, p. 47). 
mundo nele nos situando não é uma ação dada pela consciência espontânea, trata-se antes de um lançar-se que o sujeito é por inteiro em espontaneidade ambígua, onde há uma intencionalidade corporal efetiva que encarna e dá a espessura de ser vivida como solo, isto feito pelo corpo com a consciência. Assim, como será explicado, esse distanciamento negador da consciência, seja no situar-se corporal ou no uso efetivo da reflexão, não é absoluto, é ambíguo, e precisamente por isso que ela critica a perspectiva de Cinéas que seria justamente a de imaginar que a atividade da consciência é primeira e capaz de negar radicalmente ${ }^{8}$.

O exemplo dado por Beauvoir no texto é elucidativo sobre isso:

'Eu descubro que nenhum propósito valeria a dificuldade de nenhum esforço', diz o herói de Benjamin Constant. Assim pensa frequentemente o adolescente assim que a voz da reflexão [voix de la refléxion] desperta [s'éveille] nele. Criança, ele se assemelharia a Pirro: ele correria, ele jogaria sem se colocar alguma questão e os objetos que ele criaria [...] portariam neles mesmos sua razão de ser [...] (BEAUVOIR, 2013, p. 202).

A colocação da transição da infância para a adolescência em relação ao despontar da "voz da reflexão" não é gratuita; tem-se aqui a postulação de uma diferenciação entre os momentos da existência de um indivíduo, pois na infância a atividade de abstração do concreto seria ainda fraca em relação à experimentação do mundo, de tal modo que a razão de ser dos objetos seria mais vivida do que pensada, somente no desenrolar de seu amadurecimento é que começaria a ficar mais marcante a atuação da consciência. Portanto, é preciso logo de início marcar que "a reflexão não pode parar o élan [élan] de nossa espontaneidade" (BEAUVOIR, 2013, p. 203), dado que essa espontaneidade primeira é aquela que nos lança no mundo e nos abre à experimentação viva deste, é o que fornece o "solo" necessário à negatividade ambígua posterior da consciência.

Indica-se então, desde já, que para Simone de Beauvoir essa discussão sobre a possível indiferença de nossas ações deverá desenrolar-se a partir de outra perspectiva, dado que o que pode parecer inútil ou vão do ponto de vista do distanciamento nadificador, muitas vezes "é necessário do ponto de vista da condição humana" (BERGOFFEN, 1997, p. 48) vivida na presença situada ambígua.

\footnotetext{
${ }^{8}$ Ainda em relação à passagem anteriormente destaca da conclusão, Beauvoir diz: "Mas uma vez que esse vazio [vide] é apenas avesso [un envers], uma vez que a reflexão não é possível senão após o movimento espontâneo [n'est possible qu'après le mouvement spontanée], por que lhe dar uma preponderância e condenar os projetos humanos confrontando-os com a tranquilidade do nada?" (BEAUVOIR, 2013, p. 313). Assim, trata-se de ver neste trabalho a construção da autora que justifica e desdobra tal afirmação, ou seja, que explicita propriamente as características dessa estrutura existencial ambígua.
} 
Após essa colocação Beauvoir faz recurso a uma metáfora que será fundamental para todo o texto e sua compreensão de situação e subjetividade, metáfora esta que deve ser tomada como de suma importância e que, no entanto, trata-se da imagem evocada pela ideia de jardim a partir de uma citação extraída do capítulo XXX da obra Cândido de Voltaire. A autora nos apresenta a máxima aí contida que diz "É preciso cultivar nosso jardim", e em seguida ela acrescenta que "este conselho não nos será de grande ajuda. Pois, qual é meu jardim? Existem homens que pretendem cultivar a terra inteira; e outros acharão um vaso de flores muito vasto" (BEAUVOIR, 2013, p. 203). Assim, Beauvoir aponta que a máxima de Cândido não é suficiente posto que é preciso primeiro ser indicado qual é propriamente meu jardim, ou seja, minha "porção de terra" do mundo que cabe-me cultivar para que então eu possa dar conteúdo concreto a essa exortação. Em suma, como ficará claro ao longo do primeiro capítulo da primeira parte do ensaio, chamado "Le jardim de Candide", é pela metáfora do jardim que Beauvoir trabalhará a sua compreensão de situação, bem como as demais questões que lhe são correlatas. Voltemo-nos ao parágrafo inicial dessa parte onde Simone de Beauvoir diz:

\footnotetext{
Eu conheci uma criança que chorava, pois o filho de sua zeladora havia morrido; seus pais o deixaram chorar, e em seguida eles tornaram-se zangados. "Apesar de tudo este menino não era seu irmão". A criança enxugou suas lágrimas. Mas este foi um ensinamento perigoso. Inútil chorar por um menino estranho: de acordo. Mas por que chorar por seu irmão? [...] Por que chamar meus este sol, esta mulher, estas crianças? [...] não existe nenhuma ligação entre eles e eu. Assim pensa o estrangeiro de M. Camus; ele se sente estrangeiro no mundo inteiro que lhe é completamente estrangeiro. (BEAUVOIR, 2013, p. 208).
}

Como mostra a passagem, Beauvoir decide iniciar a discussão sobre a indiferença da ação a partir daquilo que lhe parece ser anterior a esta indagação e, portanto, mais fundamental: trata-se de esclarecer adequadamente aquilo que nos diz respeito, que cada um pode chamar de $s e u$, pois é em relação a isto que nossas ações adquirem significação. Este $m e u$, entretanto, assume já aqui duas características fundamentais: trata-se de algo que envolve meu lugar no mundo, minha situação, metaforicamente marcada como jardim; e, por fim, envolve necessariamente os outros, quer dizer, ter um meu como situação e realização de si é já simultaneamente ter outros como próximos, em uma unidade ambígua inevitável. Assim, seria por supostamente não nos dizer respeito, não ser nada nosso, que chorar pela morte de um outro seria inútil. Porém, como indicado pela autora, trata-se de um ensinamento perigoso, pois pode ser estendido mesmo àqueles cuja relação conosco já está constituída, 
uma vez que é uma perspectiva que se afasta das relações vivas efetivas, os laços afetivos nos quais estamos enredados com os outros para julgá-los pela exterioridade, pela distância do olhar abstrato nadificador, que é o mesmo que ver nosso ser no mundo como meros objetos. Ou seja, "se eu me isolo em mim mesmo, o outro está também fechado para mim" (BEAUVOIR, 2013, p. 208). .

Beauvoir então concorda inicialmente com esta perspectiva estrangeira, quer dizer, "o estrangeiro de M. Camus tem razão de recusar todas estas ligações que pretendem nos impor de fora; nenhuma ligação é dada primeiramente"(p. 209). Porém, esta não pode ser a última palavra, pois a relação à qual a autora dedica-se aqui não é aquela entendida como a identificação a algo exterior, trata-se antes de uma relação continuamente vivida e recriada no âmago de nossa presença no mundo frente aos demais.

Segundo Beauvoir (2013, p. 210):

É meu somente aquilo no qual eu reconheço meu ser [reconnais mon être], e não
posso reconhecê-lo senão lá onde ele está engajado [engagé]; [...] A única realidade
que me pertence é meu ato [mon acte]. [...] O que é meu é primeiramente a
realização de meu projeto [l'accomplissement de mon projet]; [...] É porque minha
subjetividade [subjectivité] não é inércia, não é dobramento [repliement] sobre si,
separação, mas ao contrário, é movimento em direção ao outro [mouvement vers
l'autre], que a diferença é abolida e então posso chamar o outro meu; a ligação que
me une ao outro só eu posso criar, e o crio pelo fato de que não sou uma coisa mas
um projeto [projet] de mim em direção ao outro, uma transcendência [une
trasncendance]. [...] nenhuma posse é dada; mas a indiferença estrangeira do mundo
também não é dada: eu não sou primeiramente uma coisa, mas espontaneidade
[spontanéité] que deseja, que ama, que olha, que age.

A colocação de que sou primeiramente uma espontaneidade "que ama, que deseja" enfim, que enreda-se em relações vividas, relaciona-se diretamente com o "élan" mencionado anteriormente. Antes de me fazer ser qualquer coisa no mundo, antes de constituir-me subjetivamente a partir da realização de meu projeto, já sou essa espontaneidade ligada com os outros neste mundo, e tal ligação é sempre retomada e recriada "um minuto pós o outro" pelo fato de que sou fundamentalmente um ir além deste estar entrelaçado primeiro visando estabelecer outras relações vivas que por sua vez serão pontos de partida para outras futuras, indefinidamente; em suma, sou "uma transcendência".

Dessa forma, a subjetividade é colocada como se constituindo em movimento espontâneo para fora de si, movimento este que é antes projeto, ou seja, é um lançar-se em abertura a partir de um solo primeiro, que vai traçando seus contornos à medida que segue em direção ao fim proposto, sem que haja nunca um fechamento completo sobre si. É nesse 
contínuo ir além de si da transcendência que nosso ser é desvelado, onde o reconhecemos na ação por meio da qual este se faz desde sempre já marcado pelo encontro vivo com o outro. Como apontou Beauvoir, aquilo a ser chamado de meu enquanto lugar no qual reconheço a mim mesmo, meu ser, só pode ser meu ato, pois é neste que marco minha singularidade enquanto aquele que faz projeto de si para ser sempre e somente neste projeto. Ou seja, nossos atos só ganham corpo em um mundo já desvelado pelos demais, já marcado pelos significados e relações que serão a matéria de meus projetos, e é a relação viva e criativa que estabeleço com esses dados para fazer algo a partir deles que é propriamente o projeto no qual me reconheço pelo engajamento de minha espontaneidade.

Portanto, como aponta Andrea Veltman (2008, p. 115), transcendência nesse texto "refere-se menos aos movimentos de uma subjetividade consciente intencional e mais às atividades construtivas que situam e engajam o indivíduo com outras liberdades humanas". Tem-se aqui o apontamento preciso da comentadora de que há claramente um distanciamento em relação a Sartre, pois, apesar da aceitação de Beauvoir da postulação sartriana da transcendência como característica fundamental da existência humana no seu ir além do dado, naquele trata-se de fato de uma atividade exclusiva da consciência intencional para fora de si, ainda que seja colocada no cogito pré-reflexivo, pois não haveria espontaneidade fora do domínio dessa consciência, e tal atividade transcendente é a negação do dado na qual dar-se-ia propriamente a subjetividade 9 . Porém, como vimos, Beauvoir admite uma transcendência ambígua do sujeito, na qual a atividade negadora da consciência é dada de modo tardio, e é essa espontaneidade ambígua carnal que nos enreda no mundo com os outros, de modo que a transcendência propriamente da consciência que nos faz despontar deste solo e abre a constituição de uma subjetividade reflexiva posterior é retomada e recriação deste "estar enredado", não sendo, portanto negação do dado como se desenraizando dele, mas antes reconstrução contínua que o leva mais além ao ir ela mesma em direção ao porvir.

Trata-se então da compreensão de que é por meio de um vivo e genuíno envolvimento com aquilo que nos é dado, sustentado continuamente pelo nosso próprio modo de existir ativo, que preenchemos nossa existência e marcamos nossa subjetividade nesse ir além sempre recomeçado. Entretanto, como já foi apontado, não se trata da construção de um "eu" enquanto identidade fixa na qual reconhecemos nosso ser, pois Beauvoir explicitamente acentua que essa subjetividade é sempre já marcada pelo outro e seus projetos, de modo que a

\footnotetext{
9 " [...] o que se pode chamar propriamente de subjetividade é a consciência (de) consciência." (SARTRE, 2016, p. 32 , grifo do autor).
} 
singularidade desponta sempre em simultaneidade com a alteridade; em outros termos, só reconheço minha subjetividade depois que esta já se enredou na situação, e os outros já a "contaminaram" com seus projetos, e assim esta permanecerá.

Após tais considerações, Beauvoir retoma sua crítica de que o conselho de Cândido é insuficiente, porém com uma colocação diferente que, à luz do que foi dito, serve para explicar melhor a noção de situação e aquelas que lhes são correlatas: as noções de subjetividade, transcendência e projeto. Assim, "é por isso que o conselho de Cândido é supérfluo: é sempre meu jardim que eu cultivarei [c'est toujour mon jardin que je cultiverai], nele estou encerrada até a morte, pois este jardim torna-se meu no momento em que o cultivo [ce jardin devient mien du moment que je cultive]"; logo no início do parágrafo seguinte ela complementa, "para que este pedaço do universo me pertença é preciso apenas que eu o cultive verdadeiramente [que je le cultive vraiment]" (BEAUVOIR, 2013, p. 213, grifo nosso).

A princípio pareceria termos aqui uma espécie de círculo vicioso, pois, se é sempre meu o jardim que cultivo, não faria sentido colocar que devo cultivá-lo para que seja meu verdadeiramente. Entretanto, na medida em que Beauvoir trabalha com a ideia de uma espontaneidade primeira que me relaciona vivamente com o mundo, e que é a retomada contínua deste solo que o faz propriamente meu, a citação perde o caráter de circularidade. A metáfora de jardim traz inevitavelmente o ato de cultivar, pois este é fundamentalmente trabalhar uma terra para que esta se torne fértil e possibilite o despontamento posterior das flores que compõem o jardim; temos ainda o fato de que o cultivo dever ser constante, posto que a terra na qual se enraíza meu jardim tornar-se-ia morta caso eu parasse de cultivá-la.

Assim, no momento em que começo a existir no mundo estou já situado, minha espontaneidade enraíza-me em uma terra dada e já trabalhada pelos outros da qual nunca poderei me desligar definitivamente, a não ser na morte. Esta terra, esse pedaço do universo é meu posto que é o solo a partir do qual posso iniciar meus projetos, mas para ser meu propriamente falando, ou seja, algo que assumo e trabalho continuamente na minha existência, é preciso que eu a cultive, que eu mantenha sempre fértil essa abertura ao cultivo. Temos então que minha situação é o estar enraizado em um solo a partir do qual faço meus projetos de ser, que são projetos de cultivo deste solo no qual florescerá o que sou; o engajarse nada mais é do que o próprio ato de cultivo que me constitui, e isto pelo fato de que sou transcendência, ou seja, sou o ir além deste solo carregado sempre em direção ao porvir posto 
que cultivo-o continuamente, nunca me desenraizando, mas antes trabalhando e refazendo esse estar enraizado.

É significativo que essa metáfora não caiba na ontologia sartriana, pois o solo que há para o para-si é mero dado bruto, passivo, simples meio para que a consciência negue e faça seus projetos de ser, projetos que não são cultivo posto que não há enraizamento. Para Sartre, a situação não constrange de nenhum modo a liberdade, pois esta não está enraizada naquela, é como se a liberdade apenas deslizasse na superfície da situação que é obstáculo contra o qual ela se choca para se exercer plenamente, ou seja, "as resistências que a liberdade desvela no existente, longe de constituir perigo para ela, nada mais fazem do que permirtir-lhe surgir como liberdade" (SARTE, 2016, p. 640, grifo nosso) ${ }^{10}$.

O movimento seguinte de Simone de Beauvoir consiste na crítica a duas perspectivas que, buscando fugir dessa tensão implicada no cultivo, buscaria reduzir ao máximo os limites do que é assumido como nosso, repousando na mera satisfação do instante ou alargá-los indefinidamente buscando-se a identificação com o infinito. Entretanto, mais do que meramente marcar a problemática dessas perspectivas em relação ao movimento ambíguo contínuo de fazer ser, está em jogo precisamente dar conta do fato de que a presença efetiva vivida com os outros nunca é negada em absoluto neste movimento. A máxima da primeira perspectiva seria "desviemo-nos do mundo, dos empreendimentos e das conquistas; não formemos mais nenhum projeto; permaneçamos em nós, em repouso no coração de nossa fruição" ${ }^{11}$ (BEAUVOIR, 2013, p. 215). Segundo a autora, tal compreensão do que seria fruir algo como um bem estaria equivocada precisamente por imaginar que isso seria obtido pela

${ }^{10}$ Destacamos outra passagem de Sartre que marca essa sua concepção: "A liberdade é um escapar a um engajamento [échappement a um engamement] no ser, é nadificação [ néantisation] de um ser que ela é. [...] o surgimento da liberdade se efetua pela dupla nadificação do ser que ela é e do ser no meio do qual ela é." (SARTRE, 2016, p. 644). Ainda, é elucidativa a colocação de István Mészáros acerca deste caráter da liberdade da consciência e sua relação com o dado".

11 A palavra em questão neste momento da discussão de Beauvoir é "jouissance", comumente traduzido por "gozo". Porém, a definição de "jouissance" em francês conforme fornecida pelo dicionário Larousse é: 1. Prazer intenso (Plaisir intense). 2. Livre uso, posse de alguma coisa (Libre usage, possession d'une chose). Ou seja, a palavra em seu idioma original carrega fortemente a ideia de que se trata de um uso que é simultaneamente livre e prazeroso de algo, o que é fundamental para as colocações de Beauvoir nesse texto e que se perde caso simplesmente seja traduzida por "gozo", posto que esta palavra em português implica mais a ideia de "ter prazer em algo". Trata-se de ressaltar que essa utilização livre e prazerosa de algo é o movimento da própria transcendência, de modo que optamos por traduzir o verbo "jouir" por "fruir" entendendo-se que esta última palavra mantém na língua portuguesa maior proximidade com a definição francesa acima apontada, posto que "fruir algo" é "fazer uso prazeroso de algo". Ainda nesse momento do texto, Beauvoir critica justamente a associação do "jouir" com um estado de repouso, que estaria mais próximo de um mero "ter prazer em", marcando que na verdade trata-se precisamente de projeto, de lançar-se em direção ao porvir, portanto, "fazer uso prazeroso de... em direção a". 
interrupção do movimento contínuo do existir, que não seria um projeto. Porém, como ela aponta:

No momento da fruição se reúne todo um passado. E eu não o contemplo somente; fruir um bem é usá-lo, é lançar-se com ele em direção ao porvir. Fruir o sol, a sombra, é experimentar a presença como um lento enriquecimento. [...] Toda fruição é projeto. (BEAUVOIR, 2013, p. 217, grifo nosso).

Sentir a relação com algo como um bem prazeroso à nossa existência é afirmar sua presença como um "lento enriquecimento" de uma relação viva e afetiva passada com o mundo na qual estávamos inseridos, o que implica uma simultânea afirmação do porvir que se abre a mim nessa própria fruição presente. Em suma, o movimento da transcendência, que é o movimento do cultivo das relações afetivas e sociais, é precisamente o mesmo que está implicado em qualquer fruição, que é o cultivo do passado do nosso enraizamento no mundo com os outros que enriquece nosso presente abrindo-o ao porvir. Assim, Beauvoir marca a importância da presença ambígua do sujeito situado para a fruição, ou seja, o fato de que esta é "presença de um objeto ao qual me sinto presente: ela é presença do objeto e de mim mesmo no seio de sua diferença [présence de l'objet et de moi-même au sein de leur différence]"

Do mesmo modo, o movimento inverso de alargar os limites de nossa situação ao infinito é problemático quando assume poder prescindir do lugar efetivo que ocupamos no mundo, o que seria negar a própria situação e as relações concretas nela dadas, as quais se evanesceriam "no universal onde a presença não se distingue da ausência absoluta" (BEAUVOIR, 2013, p. 226). Ou seja, "estendido até o infinito, eis que meu lugar no mundo é totalmente apagado [s'est effacée tout] como se eu tivesse conseguido contê-lo em um ponto sem dimensão" (p. 227), o que acarreta o apagamento simultâneo das possibilidades para meus projetos, pois estas só posso encontrar dentro de um escopo provisório que minha situação me dá como solo. Novamente aqui, trata-se do problema da negação da presença ambígua carnal que se é refazendo-a continuamente.

Trata-se então, fundamentalmente, de uma problemática que surge a partir da noção de "fï" relacionada à discussão dos limites de nossos projetos. Beauvoir aponta que "a noção de fim é ambígua [ambiguë], pois todo fim é ao mesmo tempo um ponto de partida; mas tal não impede que ele possa ser visto como fim: é neste ser possível [pouvoir] que reside a liberdade [la liberté]" (BEAUVOIR, 2013, p. 223). Temos assim uma definição importante de liberdade que é precisamente o fazer constante em presença situada dos fins como novos pontos de partida, ou seja, ela é o cultivo mesmo em direção ao outro e ao porvir que nos é dada em 
situação e que faz essa ambiguidade do fim. Aquilo que cultivamos como nosso projeto, nosso ser, precisa dos limites que são traçados no próprio movimento espontâneo que nos engaja em direção a certos fins, assim como dos limites que os outros colocam ao fazerem parte da constituição deste solo a partir do qual nos lançamos. Portanto, há uma ambiguidade na finalidade que é fundamental para nossas ações, pois tanto os limites que me são dados quanto aqueles que estabeleço a partir destes são sempre desde já abertura a novos fins, e esta ambiguidade deve sempre ser observada para que não se incorra na postulação da necessidade da ausência de fins ou da admissão de um fim absoluto que justifique todas nossas ações de uma vez por todas. Em outros termos, a existência humana é a retomada constante das relações nas quais nos enraizamos exteriorizada em atos, a relação entre a experiência individual e a realidade universal é ambígua uma vez que o próprio cultivo é ambíguo, este é um despontar para além de um solo que simultaneamente o traz consigo ao trabalhá-lo indefinidamente. Portanto, o fim é sempre já ponto de partida tanto na consideração de meu projeto situado com o projeto dos outros, onde meu fim projetado modifica a situação virando novo sololponto de partida para os outros, quanto na consideração da sua vivência interna ao projeto, pois meu fim é continuamente reafirmado e refeito como modo como me lanço na constante retomada que faço da situação para realizá-lo.

A tentativa de negação dos limites, que é a tentativa de inutilizar a postulação de fins provisórios - tanto pela recusa de se sair do instante quanto pela identificação a fins infinitos Beauvoir já mostrou ser equivocada como vimos anteriormente. A autora buscará então nesse momento do texto dar conta da outra atitude problemática que seria a busca de um único fim último universal. Assim:

O homem não pode nem reduzir indefinidamente seu ser, nem o dilatar ao infinito; ele não pode encontrar o repouso; [...] toda interrupção [arrêt] é impossível pois a transcendência [trasncendance] é um perpétuo exceder [dépassement]; mas um projeto indefinido é absurdo pois ele não conduz [aboutit] a nada. O homem sonha aqui de um ideal simétrico ao Deus incondicional que chama o pensamento especulativo, ele reclama um fim incondicional de seus atos, de tal modo que ele não possa ser excedido [dépassée], um termo tão infinito e acabado no qual sua transcendência se recuperaria [se ressaisirait] sem se limitar. (BEAUVOIR, 2013, p. 230).

O problema desse recurso a Deus enquanto possibilidade última de "salvar" nossa transcendência diz respeito, primeiramente, ao fato de que este é representado como o universal dotado de uma plenitude de ser que é estranha ao ser humano, de modo que a necessidade de nossa transcendência de fazer seu um objeto para que possa realizar-se é 
perdida uma vez que "o universal é silêncio [...] [e] o homem não pode se transcender em Deus se Deus está já inteiramente dado" (p. 230). Em segundo lugar, ainda que seja admitida uma relação entre o ser humano e Deus a partir da perspectiva de uma obediência do primeiro à vontade do segundo, permanece a problemática pois sempre cabe ao indivíduo apenas a exigência de dar conta da voz de Deus para decifrar sua vontade. Sempre estamos "em situação [situation] em relação a Deus; e eis que Deus aparece então em situação em relação ao homem" (p. 233), de modo que sua vontade só pode traduzir-se em termos humanos, e os bens que esta colocaria a serem alcançados só podem ser decididos em nome de um bem humano, de modo que ainda assim é uma decisão pautada pela vontade humana que fala em nome deste universal.

Entretanto, o argumento central dessa discussão gira em torno da noção de apelo, que Beauvoir introduz ao final dela, como preparação para o capítulo seguinte onde tal noção aparecerá mais claramente. A questão mais importante, portanto, é que "é através dos homens que o apelo [appel] de Deus se fará sempre entendido, e é pelos empreendimentos humanos que o homem responderá a esse apelo" ((BEAUVOIR, 2013, p. 236). O universal é silencio, pois não está enraizado em nenhuma situação, não é presença ambígua situada, não está entrelaçado em nenhuma relação viva comigo, por isso não me dirige nenhum apelo. Somente quando os indivíduos situados estipulam qual seria a "voz" de Deus, sua vontade, é que eu teria propriamente algo que me solicita a agir.

"É preciso então nos voltar para os homens" (p. 237), como aponta a autora no início do capítulo L'humanité. Porém, não se trata de tomar esta como "uma unidade enquanto totalidade que busca se realizar, e que ela nos apela [appelle] de uma só voz" (p. 239), no qual esta apareceria como um fim absoluto tal como é feito com Deus, mostrando-se também como uma unidade significativa atemporal e determinada a priori possível de ser abarcada de maneira completa e definida exteriormente às situações humanas no mundo. Trata-se aí da compreensão de humanidade presente no que Beauvoir chama de "mito da solidariedade" [mythe de la solidarité], que acreditando poder-se agir pela humanidade, tem como pressuposto que a representação adequada dos indivíduos é a que os toma "como partes de um organismo" de modo que "trabalhando para alguns deles nós trabalharíamos por todos" (p. 239). Ou seja, tem-se aqui a ideia de uma harmonia pré-estabelecida que define exteriormente os lugares do agir humano que funcionariam harmoniosamente para o funcionamento do todo.

Outra perspectiva criticada pela autora seria a do "Mito da evolução" [mythe de l'évolution], que, aceitando que não há uma harmonia a priori e que o agir humano toma 
frequentemente a forma de oposição, postularia, no entanto, que para além destas poderíamos encontrar uma "reconciliação mais elevada" (p. 242). Tal como a concepção anterior, trata-se de uma má compreensão do que seria situação, porém aqui mais especificamente diz respeito às consequências desta para o agir. Pois admitir essa evolução que recupera as oposições seria admitir que meus atos são inteiramente retomados pelos outros, cristalizando-se em algo dado que segue indefinidamente seu desenrolar. Como aponta Beauvoir (2013, p. 244):

\begin{abstract}
Um ato [acte] lançado no mundo não se propaga ao infinito como a onda da física clássica; é na verdade a imagem proposta pela nova mecânica ondulatória que seria conveniente aqui: uma experiência pode definir uma onda de probabilidade e sua equação de propagação; mas ela não pode prever a experiência posterior que lançará no mundo os dados novos a partir dos quais ela precisaria reconstruir a onda novamente. $\mathrm{O}$ ato $[\ldots]$ é retomado [ressaisi] pelas consciências estrangeiras; não é nunca para o outro um contrato cego [contrainte aveugle].
\end{abstract}

Segundo a autora, a humanidade só é pensada adequadamente se sua compreensão estiver em consonância com o fato de estarmos sempre em situação em relação aos outros, que cada projeto de cultivo desta é apelo em direção aos outros, que serão retomados por estes a partir de seus próprios projetos de cultivo, implicando que "eu não sou instrumento para uns senão me tornando obstáculo para os outros", não posso "servir a todos" (BEAUVOIR, 2013, p. 241). Portanto, um agir humano "não se transcende pela humanidade: é a humanidade que se transcende através dele" (p. 247).

Simone de Beauvoir coloca então o ser humano como estando no mundo de dois modos, a partir da noção de situação: como transcendência que se lança ao futuro cultivando seu passado e solo presente, e ao mesmo tempo como objeto a ser transcendido pelos demais na relação de suas situações, como separação que abre para o engajamento vivo em direção ao que é outro e simultaneamente ligação dada e recriada neste próprio movimento de cultivo. A ambiguidade observada nos fins relativos a nossos projetos deriva dessa ambiguidade encontrada na consideração da liberdade da transcendência de cada ser humano; ambígua portanto a relação da experiência individual com a realidade universal. Encontramo-nos ainda com uma subjetividade ambígua, posto que se constitui precisamente por esse movimento livre do cultivo, que implica uma repetição que retoma seu solo, e simultaneamente uma criação para além dessa retomada, sem negá-la.

Dessa forma, atender aos apelos das situações humanas singulares e suas relações é participar do movimento incessante que estabelece "as exigências e os apelos [appels] os quais não serão respondidos senão pela criação de novas exigências” (p. 247). A noção de 
apelo então adquire centralidade para o texto de Beauvoir ${ }^{12}$, pois se trata de uma definição mais detalhada da condição existencial característica do ser humano; vimos inicialmente que nosso ser, enquanto lançado gratuitamente no mundo, é pura espontaneidade na busca de constituir-se através de seus projetos, porém, uma vez que é preciso que haja mundo para que tais projetos ocorram e é sempre na relação com o outro que este se configura, Simone de Beauvoir detalha mais sua definição em que nossa espontaneidade ontológica mostra-se em situação como apelo, como movimento que chama o outro para dar significação a meus atos ao mesmo tempo em que atende ao apelo destes.

Em suma, na estrutura ontológica dada por Beauvoir, o distanciamento negador, como já indicado antes, só se efetiva por ter um solo material que lhe dá um "peso" do qual aquele nunca se desfaz pois é condição de possibilidade de seu destacar. Justifica-se que Beauvoir trabalhe com a estrutura do apelo, justamente por colocar que a situação apela à minha espontaneidade primeira na qual esta se enraíza e, cultivando-a a partir do que retoma dos outros, apela ao cultivo a ser feito pelos outros; apelamos uns aos outros para a construção de uma situação comum, pois, ainda que esta retomada recíproca venha a se dar como oposição, trata-se de uma oposição que desponta em um mesmo solo comum assumido e trabalhado.

É elucidativo sobre isso apontar a marca do que a autora coloca como uma "falsa subjetividade" [fausse subjectivité] que seria a pretensão de "separar o projeto do fim e o reduzir a um simples jogo, a uma diversão" (BEAUVOIR, 2013, p. 222), quer dizer, negar a dimensão de contínua sustentação na situação do fim que a subjetividade faz ao realizar-se. Sugere-se então, a partir do que já foi dito, que uma subjetividade assumida autenticamente seria aquela que se reconhece enquanto falta que chama um dado ao ser por este chamada e, mesmo não havendo um "eu" fechado e absoluto que a caracterize, há ainda um "si" que é projeto de "si" a partir do modo como o apelo é assumido e constituído em situação, em relação indissolúvel com o apelo dos outros e marcada pela ambiguidade inevitável dos fins. Ou seja, subjetividade é processo contínuo e ambíguo de construção de si e do dado assumido, um sair de si como apelo-resposta à situação que é assim retrabalhada; trata-se do que se é enquanto produtividade situada que interioriza um todo-situação, assumindo uma

\footnotetext{
${ }^{12}$ Destacamos aqui o breve apontamento de Ursula Tidd acerca da importância da noção de apelo para o texto de Simone de Beauvoir em questão: "Um importante conceito na sua discussão sobre as relações entre as outras pessoas é o de 'apelo', o qual Beauvoir introduz em Pyrrhus et Cinéas para significar um modo autêntico de conexão entre os seres humanos. Apelar para outra pessoa é um modo de estabelecer uma relação entre dois seres humanos transcendentes que respeita suas subjetividades individuais ao mesmo tempo em que estabelece uma ponte na distância entre eles" (TIDD, 2004, p. 36).
} 
espessura de ser onde se "cava" seu lugar, sendo este último a exteriorização de si que já é sempre uma nova retomada e reorganização desse solo.

Tem-se assim que é em situação que nossas ações são justificadas nessa postulação ambígua de fins constantemente atravessando e sendo atravessados pelos fins dos outros. Porém, essa justificação a ser dada pelo outro não deve recair naquilo que Beauvoir apresenta como uma "moral da dedicação [dévouement]" que seria ver o valor da vida do outro com um fim absoluto. Nesse caso, haveria o esquecimento do fato de que somos sempre e simultaneamente sujeito e objeto uns para os outros, e o problema estaria justamente em considerar o outro como um sujeito absoluto capaz de me justificar enquanto pura passividade, ou seja, enquanto eu seria somente objeto. Ainda, outro problema dessa moral seria que "recorrentemente ela toma uma figura mal humorada e tirânica: é sem ele, contra ele que nós desejamos o bem do outro" (BEAUVOIR, 2013, p. 267); tal ocorreria na atitude de colocar o outro como mero objeto a ser fundado por mim, quer dizer, admitir que podemos estabelecer um fim fechado que seria o bem último da vida do outro.

É preciso então que saibamos claramente que nós só criamos para a vida dos outros pontos de partida, e que são vistos simultaneamente como fins, ou seja:

\begin{abstract}
O homem generoso sabe bem que sua ação atinge somente os arredores do outro; tudo que ele pode demandar, é que esta ação livre não seja confundida por aquele que é beneficiado, como uma pura facticidade sem fundamento: que ela seja reconhecida como livre [...]. no reconhecimento [...] é preciso que seja possível de manter face a face estas duas liberdades que parecem se excluir: a do outro e a minha; é preciso que eu me apreenda de uma vez como objeto e como liberdade, que eu reconheça minha situação como fundada pelo outro ao afirmar totalmente meu ser para além da situação (BEAUVOIR, 2013, p. 277).
\end{abstract}

É esta generosidade que Beauvoir chama de lúcida, que abre para uma verdadeira solidariedade e, portanto, deve guiar nossos atos; agir para e com o outro é "responder ao apelo [appel] que emana de sua vontade" (BEAUVOIR, 2013, p. 268) e vem ao meu encontro, é estabelecer uma comunicação significativa a partir daquela em que já estamos inseridos para que nossos atos não recaiam sobre si mesmos e fiquem inertes e indiferentes. Beauvoir nos apresenta então um exemplo significativo:

É o erro das teorias tais como a da arte pela arte de imaginar que um poema ou um quadro são uma coisa inumana que é autossuficiente [suffit à soi seul]: é um objeto feito pelo homem, para o homem. Certo, ela não é feita nem para distrair, nem para edificar, ela não responde a uma necessidade [besoin] que existiria diante dela a qual ela deveria preencher; ela é ultrapassamento [dépassement] do passado, invenção gratuita e livre; mas na sua novidade ela exige ser alcançada e justificada, é preciso 
que os homens a amem, a queiram, a prolonguem. $\mathrm{O}$ artista não poderia se desinteressar da situação dos homens que o circundam. No outro está engajada sua própria carne [chair] (BEAUVOIR, 2013, p. 305, grifos nossos).

O exemplo do artista dá-se como significativo para todo agir humano que, cultivando sua situação, cria algo novo que fará então parte da situação dos outros. Assim, a justificativa daquilo que cultivo pelos meus atos não pode ser dada pelo simples fato de que eu o tenha cultivado, pois, uma vez que minha carne está engajada na situação dos outros a partir da minha espontaneidade primeira ${ }^{13}$ - uma espontaneidade corporal -, é preciso então que eu modifique a minha situação pelo agir tendo em vista que uma vez terminado, meu cultivo passa a ser ponto de partida para outros, é apelo a ser retomado vivamente por eles. Apenas se houver essa incorporação feita pelos outros é que as consequências do meu cultivo permanecerão abertas, ainda para mim no porvir e poderei continuar fazendo-as minhas, uma vez que só faço ser propriamente meu aquilo que a minha situação enquanto trabalhada pelos outros me entrega.

Beauvoir busca marcar a importância da comunicação para a análise de nossas ações, uma vez que o lugar no qual a separação entre eu e os outros é excedida em direção à reconstrução contínua de uma ligação por meio de projetos, é precisamente onde encontramos as justificativas para nossas ações e, portanto, sua significação mais fundamental. É em um mesmo movimento em direção ao que é outro, que nossa espontaneidade constitui-se subjetivamente enquanto comprometimento vivo para reconhecer seu ser, e simultaneamente está engajada na construção das possibilidades que se abrem ao demais. Ou seja, "na comunicação com o outro nós buscamos o desenvolvimento do projeto onde nossa liberdade se engaja; e é preciso então que o outro me projete sobre um porvir que reconheço para mim" (BEAUVOIR, 2013, p. 299); assim, perde-se a aparência vã dos meus projetos enquanto compreendidos meramente sob a ótica da abstração, pois agora estes aparecem como significativos nos projetos dos demais. Fundamentalmente, o mundo é desvelado como infestado de apelos a serem atendidos, e nosso ser é dado sobre esse fundo como um apelo a realizar-se simultaneamente com os outros que encontro sempre em situação.

E, como coloca Beauvoir, para que esta comunicação que sustenta nossa liberdade reciprocamente ocorra, são necessárias duas condições: primeiro, é preciso que eu possa dirigir um apelo ao outro, ou seja, que eu possa me colocar concretamente e espontaneamente

\footnotetext{
${ }^{13}$ Aqui se esclarece mais a questão do "élan" citado no início do texto. Ou seja, minha espontaneidade vital primeira é que enraíza minha carne na situação, e só então haverá a abertura para a espontaneidade da consciência que, tomada adequadamente, não pode ser um estancamento desse movimento livre ambíguo.
} 
como apelo a tudo aquilo não sou eu, mas participa fundamentalmente de minha situação, de modo que "eu lutarei então contra aqueles que querem sufocar minha voz, me impedir de me expressar, me impedir de ser" (BEAUVOIR, 2013, p. 306); em segundo lugar, deve-se querer que os demais estejam em uma situação igualmente aberta frente a mim e possam então responder espontaneamente a meu apelo e me chamar a responder os seus. Por fim, "para que nossos apelos não se percam no vazio, é preciso que haja perto de mim homens prontos para me entender; é preciso que [...] sejam meus pares" (p. 308), o que significa que devemos agir em duas direções simultâneas, recriando as condições e relações nas quais realizamos concretamente nossa transcendência ao mesmo tempo em que nos esforçamos para manter abertas aos demais as suas próprias possibilidades de realização, o que é fundamentalmente criar para os demais "situações tais que eles possam acompanhar e exceder minha transcendência" (p. 308). A liberdade do outro, portanto, mostra-se em situação como um chamado a mim que é atendido quando atende ao meu chamado.

O ajuizamento acerca da adequação ou não de minhas ações é mais bem colocado quando consideramos nossa situação em relação à dos demais, a partir da compreensão da interdependência de nossa liberdade situada, quer dizer, interdependência de nossa subjetividade enquanto livre espontaneidade que faz um apelo ao outro pois é sempre já resposta aos apelos dos outros. Dessa forma, admitindo-se uma preocupação ética inerente a essa condição existencial apresentada, escolhe-se agir e de determinado modo tendo-se em vista sempre que "eu demando para os homens a saúde, o saber, [...] o lazer, a fim de que sua liberdade não se consuma combatendo a doença, a ignorância, a miséria" (p. 308); ou seja, eu busco "liberar a liberdade" ${ }^{14}$ ao reconhecer que em certas situações, a possibilidade do cultivo pode estar fechada para os outros.

Desse modo, vemos que Simone de Beauvoir apresenta em Pyrrhus et Cinéas sua compreensão de situação, subjetividade e apelo a partir do uso da imagem de jardim, mostrando que nossa situação é o lugar circunscrito a partir do qual podemos ver nosso ser se desenvolver, o que implica um constante cultivo desse jardim posto que encará-lo como já acabado implicaria um descuido que torna esse solo estéril e seco. O ser que brota enquanto

\footnotetext{
${ }^{14}$ Tal expressão é da própria Beauvoir, apresentada no volume da sua autobiografia citada no início do texto, e que apresentamos aqui para maior esclarecimento de tudo que já foi dito: "Distingui dois aspectos da liberdade: ela é a própria modalidade da existência que, por bem ou por mal, retoma por sua conta tudo o que lhe vem de fora [...]. Em compensação, as possibilidades concretas que se abrem às pessoas são desiguais; algumas têm acesso a uma pequena parte das de que dispõe o conjunto da humanidade; seus esforços não fazem senão aproximá-las da plataforma de onde se lançam as mais favorecidas: sua transcendência perde-se na coletividade sob a forma da imanência. [...] uma atividade é boa quando visa conquistar para si e para os outros essas posições privilegiadas: liberar a liberdade." (BEAUVOIR, 2015, p. 710, grifos nossos).
} 
cultivo, a subjetividade despontada nesse movimento que excede seu próprio solo, não pode, portanto, não carregar aquilo que neste solo é condição de seu florescimento, esta se mostrando precisamente como esse despontar único e enraizado. De modo que o cultivo que cada um faz de seu jardim é sempre apelo ao jardim dos outros, minha situação chama sempre a situação dos demais, pois, mesmo reconhecendo a importância das cercas que nos separam, há sempre um mesmo solo que perpassa nossos jardins. O que implica assumir que nossa vida pessoal é tardia em relação a essa camada impessoal pré-reflexiva e carnal na qual nos abrimos e nos ligamos efetivamente ao mundo e aos outros.

Portanto, é Pirro que tem razão, pois o fato de que findo em algum momento qualquer projeto estabelecido não quer dizer que este perde o valor, pois o significativo é justamente a possibilidade sempre aberta de outros futuros; para que haja um mundo no qual possa assumir sua situação e chamar de sua, o indivíduo deve cultivar sempre seus projetos. A indiferença perde assim qualquer valor, pois minha situação é efetivamente minha quando crio algo sobre ela e a assumo como ponto de partida para meus projetos. Abrir mão de escolher, de agir, é abrir mão de cultivar o solo no qual nosso ser se constitui, e como este não está nunca dado $a$ priori e absolutamente, essa criação é contínua; mais, é abrir mão da dimensão de vínculo inevitável com os outros, posto que esses laços são sustentados e refeitos no fazer. Portanto, colocar-se separado do mundo é o mesmo que entregar-se à existência inerte das coisas na qual tudo é indiferente, a ação é algo supérfluo, já que a espontaneidade foi abolida, e só sobraram solidão e separação.

\section{REFERÊNCIAS}

BEAUVOIR, Simone de. Cahiers de jeunesse. Paris: Gallimard, 2008.

BEAUVOIR, Simone de. Pour une Morale de l'ambiguité suivi de Pyrrhus et Cinéas. Paris: Gallimard, 2013.

BEAUVOIR, Simone de. La force de l'âge. Paris: Gallimard, 2015.

BEAUVOIR, Simone de. Le deuxième sexe. Vol. I et II. Paris: Gallimard, 2016.

BERGOFFEN, Debra. The philosophy of Simone de Beauvoir: gendered phenomenologies, erotic generosities. New York: State University of New York, 1997.

BERGOFFEN, Debra. Introduction to "Pyrrhus and Cineas". In: SIMONS, Margaret (Org.). Simone de Beauvoir: philosophical writings. Chicago: University of Illinois Press, 2004. 
CATALANO, Joseph. A commentary on Jean-Paul Sartre's Being and Nothingness. Chicago: Chicago University Press, 1985.

KAIL, Michel. Simone de Beauvoir philosophe. Paris: PUF, 2015.

OGANOWSKI, Kristen. Centralizing ambiguity: Simone de Beauvoir and a Twenty-First century ethics.

SARTRE, Jean-Paul. L'être et le néant- Essai d'ontologie phénoménologique. Paris:

Gallimard, 2016.

SIMMONS, Margareth. Simone de Beauvoir and The second sex: feminism, race and the origins of existentialism. Maryland: Rowman \& Littlefield Publishers, 1999.

TIDD, Ursula. Simone de Beauvoir. London: Routledge Ed, 2004.

VELTMAN, Andrea. Transcendence and immanence in the ethics of Simone de Beauvoir. In: SIMONS, Margaret. The philosophy of Simone de Beauvoir: critical essays. Indiana: Indiana University Press, 2008. 